2009-01-01

\title{
Microstrip-Fed Dual-Frequency Annular-Slot Antenna Loaded by Split-Ring-Slot
}

\author{
Xiulong Bao \\ Technological University Dublin, xiulong.bao@tudublin.ie \\ Max Ammann \\ Technological University Dublin, max.ammann@tudublin.ie
}

Follow this and additional works at: https://arrow.tudublin.ie/engscheceart

Part of the Electrical and Computer Engineering Commons

\section{Recommended Citation}

Bao, X. \& Amman, M. 92009) Microstrip-Fed Dual-Frequency Annular-Slot Antenna Loaded by Split-RingSlot. IET Microwaves, Antennas and Propagation, Vol. 3, 5, 2009, pp. 757-764. doi:10.1049/ietmap.2008.0193

This Article is brought to you for free and open access by the School of Electrical and Electronic Engineering at ARROW@TU Dublin. It has been accepted for inclusion in Articles by an authorized administrator of ARROW@TU Dublin. For more information, please contact arrow.admin@tudublin.ie, aisling.coyne@tudublin.ie, gerard.connolly@tudublin.ie. Funder: National Science Foundation

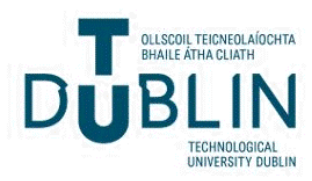




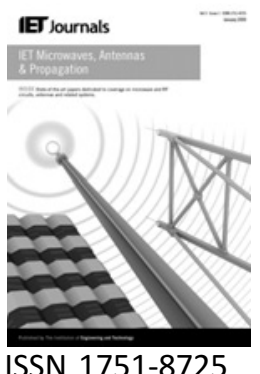

\title{
Microstrip-fed dual-frequency annular-slot antenna loaded by split-ring-slot
}

\section{X.L. Bao M.J. Ammann}

Centre for Telecommunications Value-chain Research, School of Electronic and Communications Engineering, Dublin Institute of Technology, Kevin Street, Dublin 8, Ireland

E-mail:max.ammann@dit.ie

\begin{abstract}
A compact dual-band annular-slot antenna loaded by a concentric split-ring-slot is presented. A stepped microstrip feedline enables the control of the coupling and provides good matching. The annular-slot is connected to the split-ring-slot by a rectangular slot, which increases the surface of the current path, thus notably reducing the resonant frequency for a given size. The embedded split-ring-slot structure allows many resonant modes to be realised. By tuning the key parameters, these operating modes and their bandwidths can be controlled. A wide bandwidth can be realised for either the lower band, upper band or both bands simultaneously, depending on the application. Measured results show that the bandwidths in the region of $45-15 \%$ and $32-8.4 \%$, can be provided for the lower and upper bands, respectively. For the case where a wideband response is required for both bands, it is shown that 26 and $32 \%$ can be realised. A 30\% miniaturisation is also achieved compared with conventional annular ring slot antennas.
\end{abstract}

\section{Introduction}

Annular-ring patch antennas [1-4] and annular-slot antennas [5-8] have recently attracted significant interest because of their appealing features such as relatively wide bandwidth, low profile, light weight and ease of fabrication. In general, the bandwidth for single-frequency annular-slot antennas is about $10 \%[5,8]$. The introduction of broadbanding techniques can increase this $[9,10]$. However, in the case of dual-band annular-slot antennas, it is difficult to obtain large bandwidths for both the lower and upper bands simultaneously, because the antenna impedance characteristics are different for each band.

Various techniques have been employed to achieve broadband, dual-band and multiband operation for slot antennas. An asymmetric feedline was used to excite multiple modes on an annular-ring slot, which achieves multiband operation with a $10 \%$ bandwidth for both bands by bending and adjusting the length of microstrip line [7]. Triplate linefed dual-loop slot antennas were introduced for linear and circular polarisation $[11,12]$. In subsequent reported work [13-21], annular-slot antennas have been shown to provide $10-20 \%$ impedance bandwidth, which is broader than for classical microstrip patch antennas. However, for the emerging wireless systems, a broader bandwidth is needed. These applications include combinations of WWANs, WLANs and WPANs and with diplexing now contained in many radio modules, multiband antennas offer a saving of space. Usually, broad dual-frequency characteristics are hard to realise in annular-slot antennas because good impedance matching is very difficult to achieve in multiple bands. In [22], the input impedance matching was improved and wider bandwidths obtained by using an added feed network and multiple fictitious short circuits along the slot, but this adds complexity.

In this paper, the annular-slot and concentric annular-splitring-slots are connected by a rectangular slot, thereby increasing the surface current path and enabling miniaturisation of the slot antenna obtained. By adjusting the parameters of the antenna, such as the width of the slotring, the radius of the inner and outer slot-rings and the width and length of the microstrip line, dual-frequency characteristics can be realised with combinations of narrow and wide bandwidths for one or both bands. One can realise the normally difficult to achieve wideband characteristics for both bands, and measured results show greater than 26 and 
$32 \%$ for the lower and upper bands, respectively. Another combination is a very wide bandwidth for the first band ( $>45 \%$ ) with $8.4 \%$ for the second band. When compactness is the main requirement, the miniaturised element can achieve over $15 \%$ bandwidth for both bands. This is done by shortening the length of the microstrip feedline, and good matching is achieved for the low-frequency fundamental mode.

\section{Configuration and design of concentric annular-slot antennas}

The configuration of the compact slot antenna is illustrated in Fig. 1. It consists of an annular-slot connected to a concentric annular-split-ring by a narrow rectangular slot. The slot antenna is fed by a stepped microstrip line, which provides
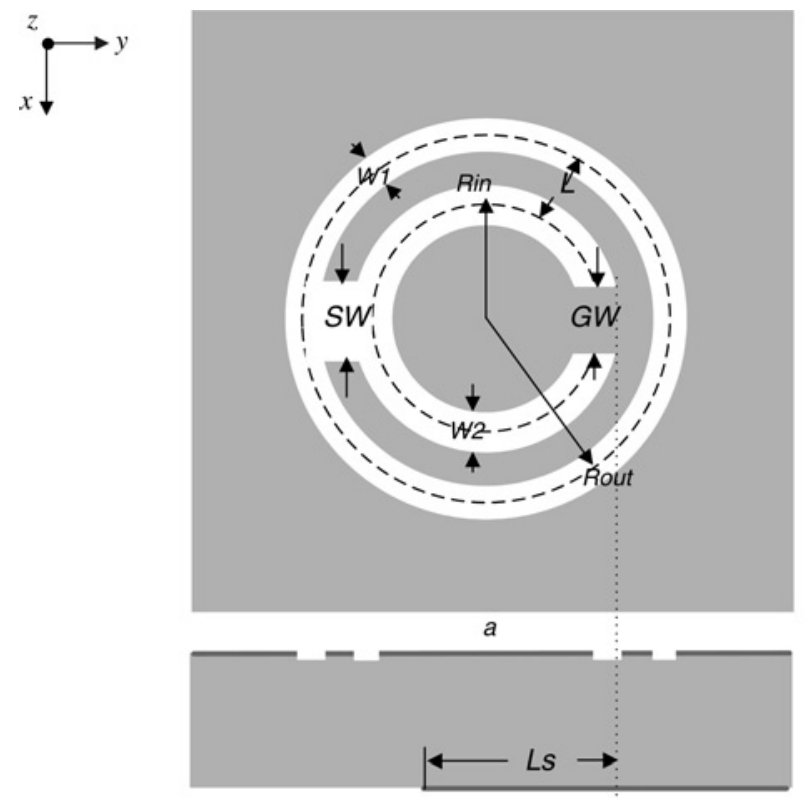

$b$

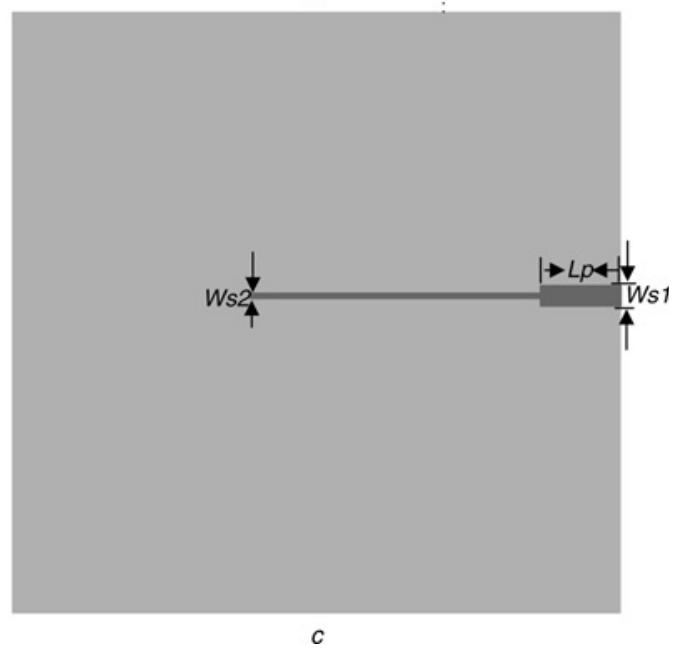

Figure 1 Configuration of the proposed antenna
a Slot configuration
$b$ Substrate
c Stepped feedline

impedance matching. Usually, the resonant frequencies are mainly determined by the circumference length of the annular-slot. For the proposed annular-slot antenna, the first mode is mainly determined by the circumference of the inner and outer slot-rings, and the second mode is mainly determined by the outer circumference. The annular-slot widths and the microstrip feedline parameters also have a significant effect on performance. An approximation [23] is given by $\lambda_{\mathrm{gs}}=2 \pi R$, where $R$ is the radius of annular-slot, $\lambda_{\text {gs }}$ is slot guided wavelength and where

$$
\begin{aligned}
\lambda_{\mathrm{gs}}= & \lambda_{0}\left\{1.045-0.365 \ln \varepsilon_{r}+\frac{6.3\left(w_{\mathrm{s}} / h\right) \varepsilon_{r}^{0.945}}{\left(238.64+100 w_{\mathrm{s}} / h\right)}\right. \\
& \left.-\left[0.148-\frac{8.81\left(\varepsilon_{r}+0.95\right)}{100 \varepsilon_{r}}\right] \ln \left(\frac{h}{\lambda_{0}}\right)\right\}
\end{aligned}
$$

To miniaturise the slot antenna, by the addition of a concentric split-ring-slot, the slot perimeter is also lengthened, thus significantly reducing the centre frequency. The slot antenna is tightly coupled to the microstrip line and hence, the feedline parameters are key factors. To achieve different dualband characteristics, it is necessary to tune and optimise the slot widths $w 1$ and $w 2$, the separation distance $L$ between the annular-slot and the split-ring-slot, and the width $w_{s 2}$ and length $L$ s of the microstrip line. The effects of these parameters on the antenna performances are discussed in the next section.

\section{Analysis and study of the parameters}

In this paper, the effects of the proposed slot antenna parameters are discussed and analysed using CST microwave studio. In comparison with patch antennas, annular-slot antennas have relatively wide impedance characteristics. Usually, for antennas with narrow annular-slots, the impedance bandwidth is only about $10 \%$, but for wider slots, greater bandwidths can be obtained, because of the reduced quality factor [22].

To reduce costs, the substrate was selected as FR4, which has a relative permittivity of 4.3 , loss tangent of 0.02 and a thickness of $1.52 \mathrm{~mm}$ ( $35 \mu \mathrm{m}$ metallisation). The ground plane size was $100 \mathrm{~mm} \times 100 \mathrm{~mm}$. Based on the simulated results, it was found that the width SW of the rectangular slot has negligible effects; the other parameters upon which the antenna performance shows a medium or heavy dependence are discussed in the following section.

\subsection{Dependence on the width of the split-ring gap GW}

Fig. 2 shows the return loss plots for different values of GW with the outer radius $R$ out $=29.5 \mathrm{~mm}, W 1=7 \mathrm{~mm}$, inner radius $R$ in $=13.5 \mathrm{~mm}, \quad W 2=5 \mathrm{~mm}, \quad G W=10 \mathrm{~mm}$, 


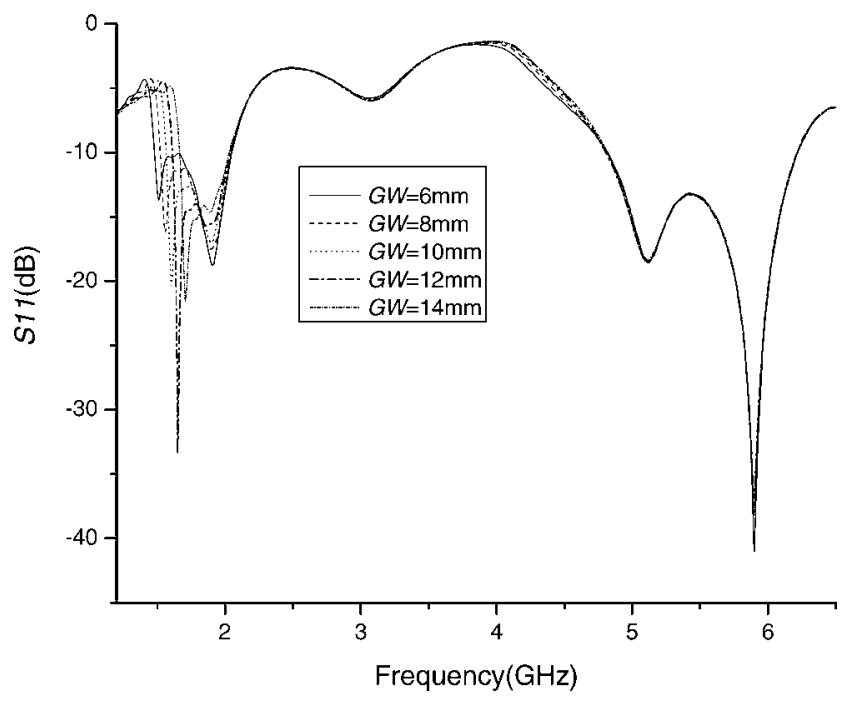

Figure 2 Comparison of S11 for different split-ring gaps GW

$\mathrm{SW}=10 \mathrm{~mm}, L p=10 \mathrm{~mm}, W \mathrm{~s} 1=3.0 \mathrm{~mm}, L \mathrm{~s}=9 \mathrm{~mm}$ and $W \mathrm{~s} 2=1 \mathrm{~mm}$. As the split-ring gap GW increases, the annular-slot length is decreased. Consequently, the lowfrequency edge will shift upwards a little with an associated reduction in bandwidth. There is no effect on the upper band. This parameter can therefore be used to independently control the bandwidth of the lower band.

\subsection{Dependence on the microstrip feedline parameters Ws2 and $L s$}

The feedline arrangement and dimensions have a significant influence on the electromagnetic coupling between the feedline and the slot. Thus, the slot antenna characteristics are heavily dependent on the parameters $W$ s 2 and Ls. A parametric study of the line was made and the other parameters were: outer and inner radii $R$ out $=29.5 \mathrm{~mm}$, $R$ in $=13.5 \mathrm{~mm}, W 1=7 \mathrm{~mm}, W 2=5 \mathrm{~mm}, \mathrm{GW}=10 \mathrm{~mm}$,

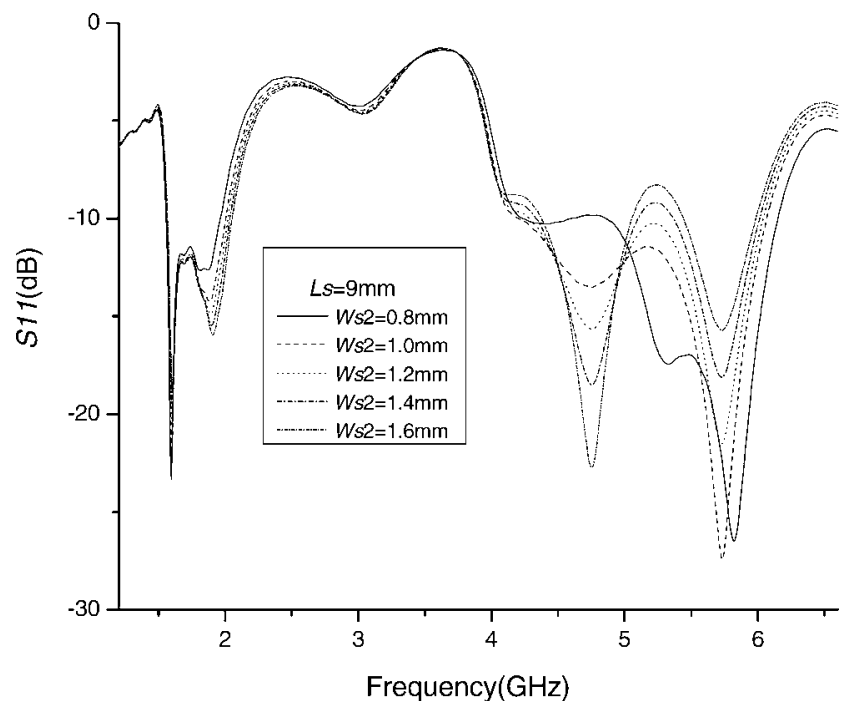

Figure 3 Comparison of S11 with different values of Ws2
$\mathrm{SW}=10 \mathrm{~mm}, L p=10 \mathrm{~mm}$ and $W \mathrm{~s} 1=3.0 \mathrm{~mm}$. Fig. 3 shows that for the lower band, the lower edge frequency remains constant whereas the upper edge frequency increases with increase in the line width $W_{\mathrm{s}} 2$; at the same time, the modes for the upper band separate. Therefore this parameter can be used to control the lower frequency bandwidth, upper centre frequency and frequency ratio.

The length $L$ s of the microstrip feed line is also an important parameter that determines the performance of the slot antenna. Wide dual-band operation can be achieved for a suitable choice of the length $L s$ as shown in Fig. 4. By adjusting the microstrip feedline length $L s$, the bandwidth of the upper band can be independently controlled. There is little effect on the lower band. It is seen from Fig. 4 that a wide variation in bandwidth is achieved by a variation of $L \mathrm{~s}$ from 7 to $10 \mathrm{~mm}$.

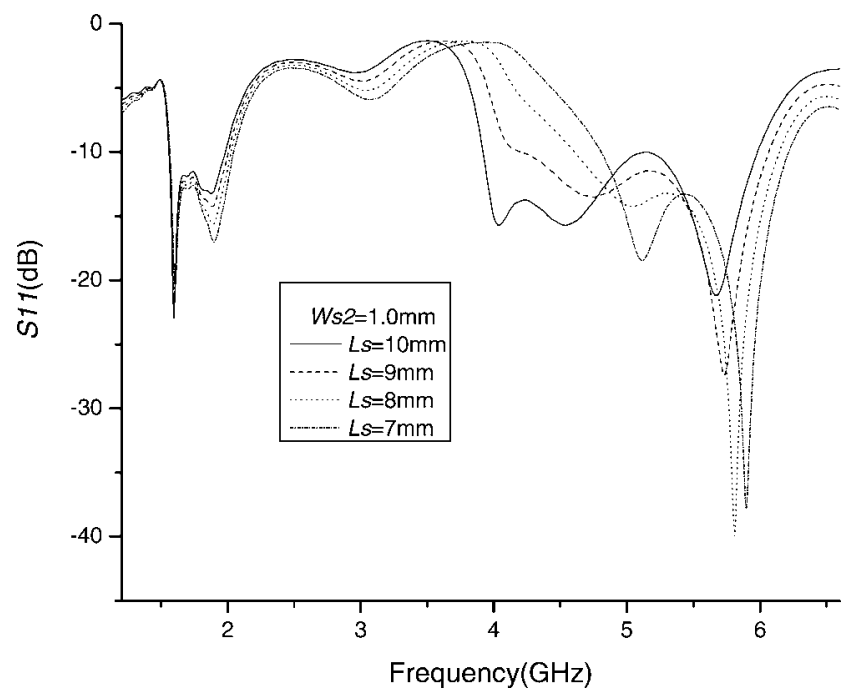

Figure 4 Comparison of S11 with different values of $L S$

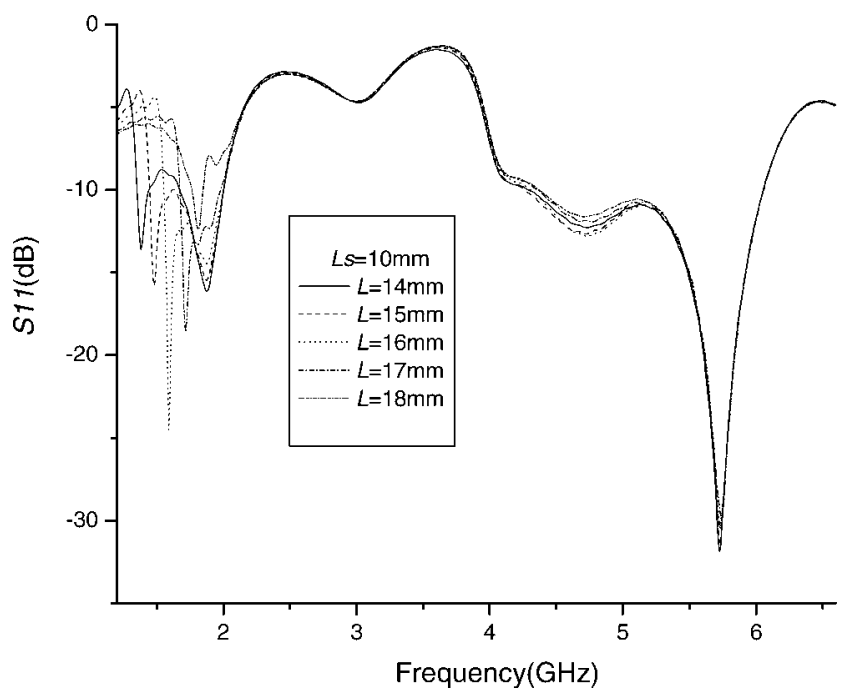

Figure 5 Comparison of S11 for different values of $L$ 


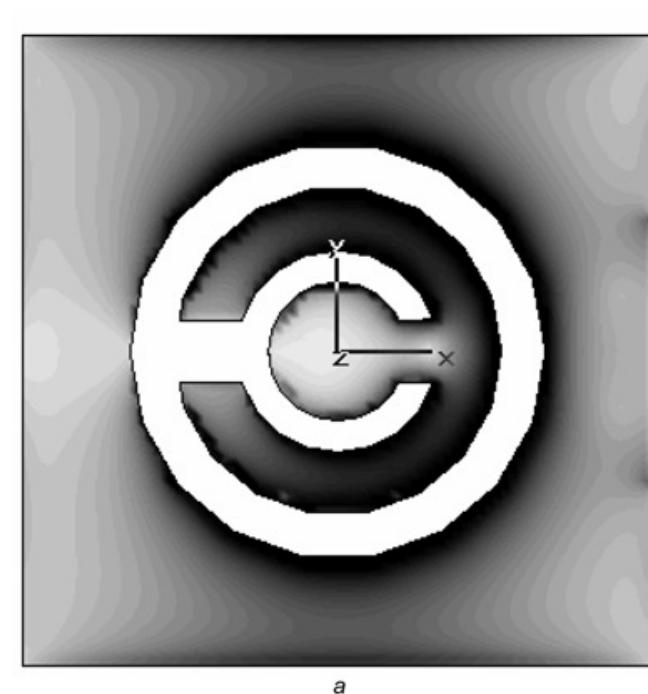

$\mathrm{A} / \mathrm{m}$
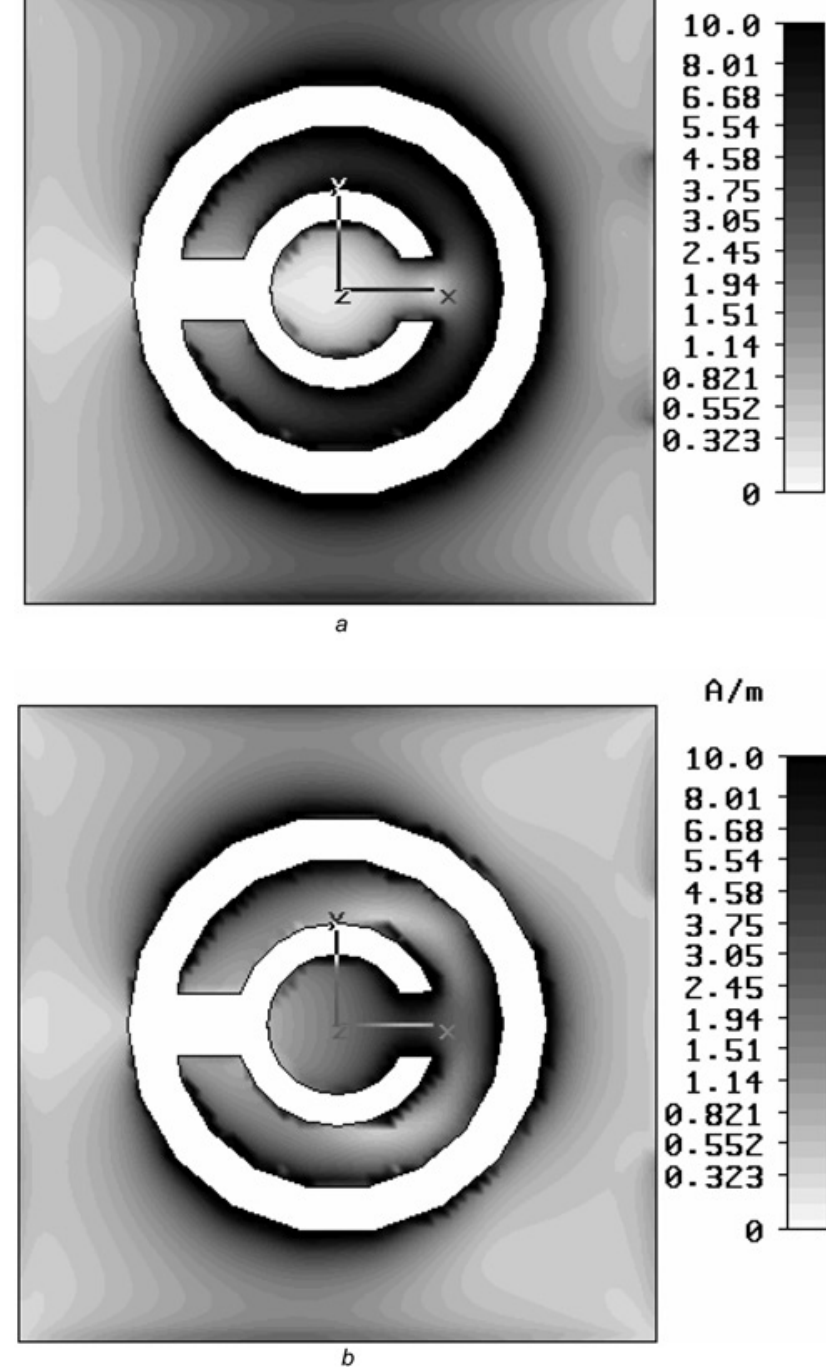

$\mathrm{A} / \mathrm{m}$

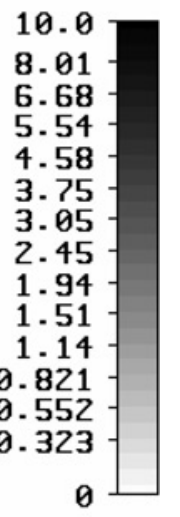

Figure 6 Surface current distribution of Antenna B at lower band and high band

a $1.165 \mathrm{GHz}$

b $1.855 \mathrm{GHz}$

\subsection{Dependence on the separation distance $L$ between the inner and outer annular-slots}

Fig. 5 displays the return loss curves against frequency for the outer radius Rout $=29.5 \mathrm{~mm}, W 1=7 \mathrm{~mm}$, $W 2=5 \mathrm{~mm}, \mathrm{GW}=10 \mathrm{~mm}, \mathrm{SW}=10 \mathrm{~mm}, L p=10 \mathrm{~mm}$, $W_{\mathrm{s}} 1=3.0 \mathrm{~mm}, L \mathrm{~s}=9 \mathrm{~mm}$ and $W_{\mathrm{s}} 2=1 \mathrm{~mm}$. It is seen that there is a downward shift for the lower band as the separation distance $L$ between the inner and outer annular-slots decreases. There is also a notable increase in the bandwidth of the lower band as this parameter decreases. Thus, as the separation distance $L$ becomes small, the first and second resonant modes become very close, providing wide bandwidth characteristics for the lower operating frequency band with negligible effects on the upper band.

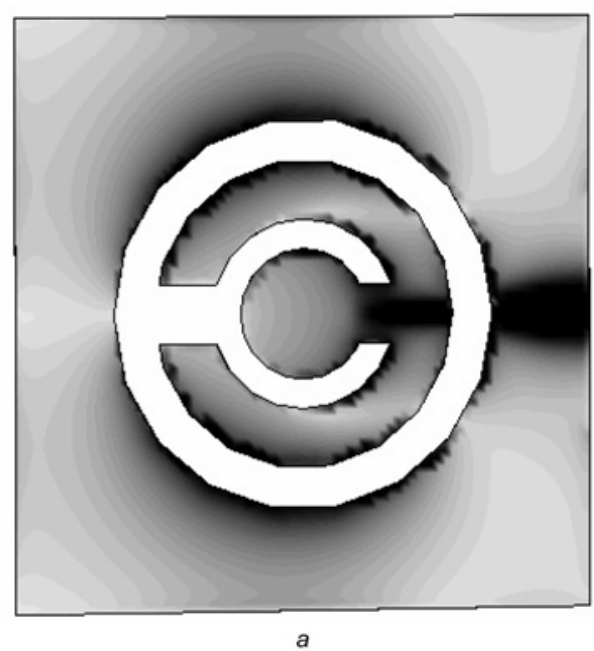

$\mathrm{A} / \mathrm{m}$

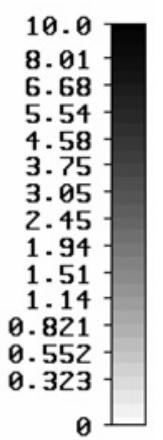

$\mathrm{A} / \mathrm{m}$

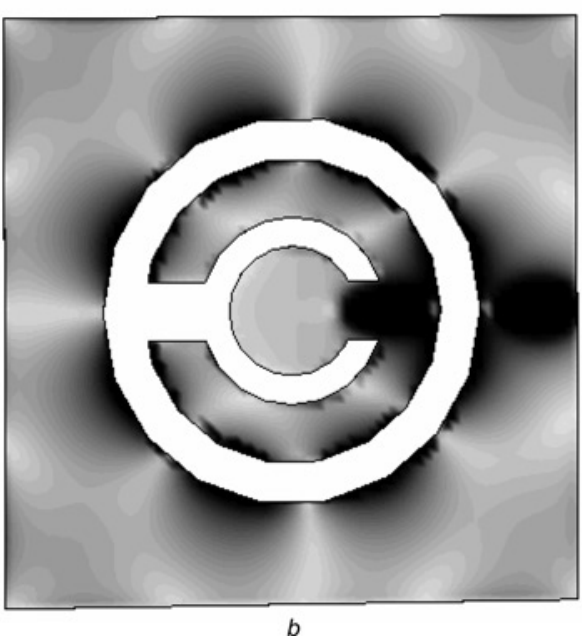

10.0

8.01

6.68

5.54

4.58

3.75

3.05

2.45

1.94

1.51

0.821

0.552

0.323

0

Figure 7 Surface current distribution of Antenna A at lower band and high band

a $1.784 \mathrm{GHz}$

b $5.132 \mathrm{GHz}$

Table 1 Three dual-frequency slot antenna parameters

\begin{tabular}{|l|c|c|c|}
\cline { 1 - 2 } \multicolumn{1}{|c|}{ Type } & \multirow{2}{*}{ Antenna A } & Antenna B & Antenna C \\
\cline { 1 - 3 } Parameters & & 29.5 & 26.0 \\
\hline Rout & 29.5 & 13.5 & 17.0 \\
\hline Rin & 13.5 & 7.0 & 4.0 \\
\hline W1 & 7.0 & 5.0 & 4.0 \\
\hline W2 & 10.0 & 10.0 & 6.0 \\
\hline SW & 10.0 & 10.0 & 10.0 \\
\hline GW & 1.0 & 1.0 & 0.40 \\
\hline Ws2 & 9.0 & 2.0 & 11.0 \\
\hline Ls & & & \\
\hline
\end{tabular}


Table 2 Comparison of measured and simulated results for Antennas A, B and C

\begin{tabular}{|c|c|c|c|c|}
\hline \multicolumn{2}{|c|}{ Type } & Antenna A & Antenna B & Antenna C \\
\hline \multicolumn{2}{|c|}{ Performances } & & & \\
\hline \multirow{2}{*}{$f 1, \mathrm{GHz}$} & simulated & 1.784 and $1.552-2.015$ & 1.165 and $1.068-1.261$ & 1.538 and $1.072-2.005$ \\
\cline { 2 - 5 } & measured & 1.796 and $1.554-2.037$ & 1.200 and $1.108-1.292$ & 1.581 and $1.227-1.935$ \\
\hline \multirow{2}{*}{$f 2, \mathrm{GHz}$} & simulated & 5.132 and $4.210-6.055$ & 1.855 and $1.592-2.118$ & 3.108 and $2.976-3.241$ \\
\cline { 2 - 5 } & measured & 5.297 and $4.438-6.156$ & 1.850 and $1.582-2.118$ & 3.016 and $2.890-3.143$ \\
\hline \multirow{2}{*}{ BW1, \% } & simulated & $26.0 \%$ & $16.6 \%$ & $60.1 \%$ \\
\cline { 2 - 5 } & measured & $26.9 \%$ & $15.3 \%$ & $45.0 \%$ \\
\hline \multirow{2}{*}{ BW2, \% } & simulated & $36.0 \%$ & $28.4 \%$ & $8.5 \%$ \\
\cline { 2 - 5 } & measured & $32.5 \%$ & $29.0 \%$ & $8.4 \%$ \\
\hline \multirow{2}{*}{$f 2 / f 1$} & simulated & 2.87 & 1.59 & 2.02 \\
\cline { 2 - 5 } & measured & 2.95 & 1.54 & 1.92 \\
\hline
\end{tabular}

Table 3 Sensitivity of the antenna centre-frequency and bandwidth to geometric parameters

\begin{tabular}{|l|c|c|c|c|}
\hline \multirow{2}{*}{ Parameters } & \multicolumn{2}{|c|}{ Lower frequency } & \multicolumn{2}{c|}{ Upper frequency } \\
\cline { 2 - 5 } & Centre frequency & Bandwidth & Centre frequency & Bandwidth \\
\hline GW & none & heavy & none & none \\
\hline Ws2 & light & light & heavy & heavy \\
\hline Ls & light & heavy & heavy \\
\hline$L$ & heavy & none & light \\
\hline dielectric constant, $\varepsilon_{r}$ & \multicolumn{2}{|c|}{ light } \\
\hline
\end{tabular}

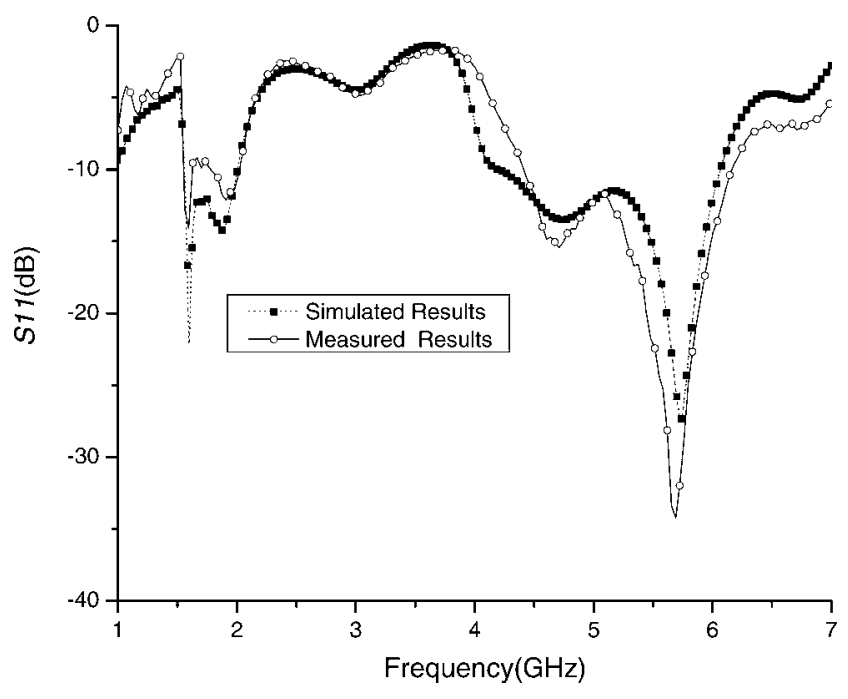

Figure 8 Comparison of the simulated and measured S11 for Antenna A

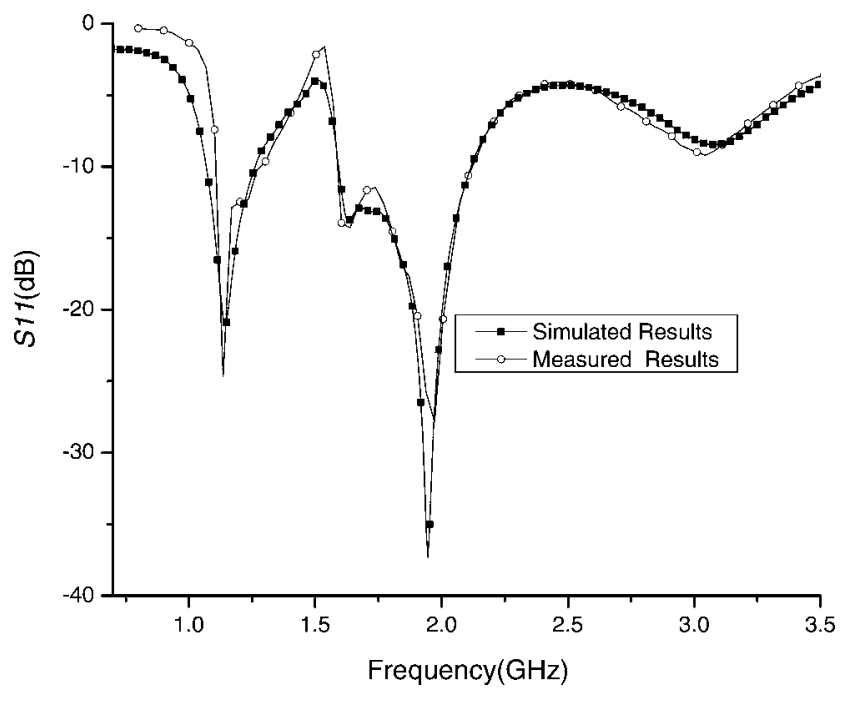

Figure 9 Comparison of the simulated and measured S11 for Antenna B 


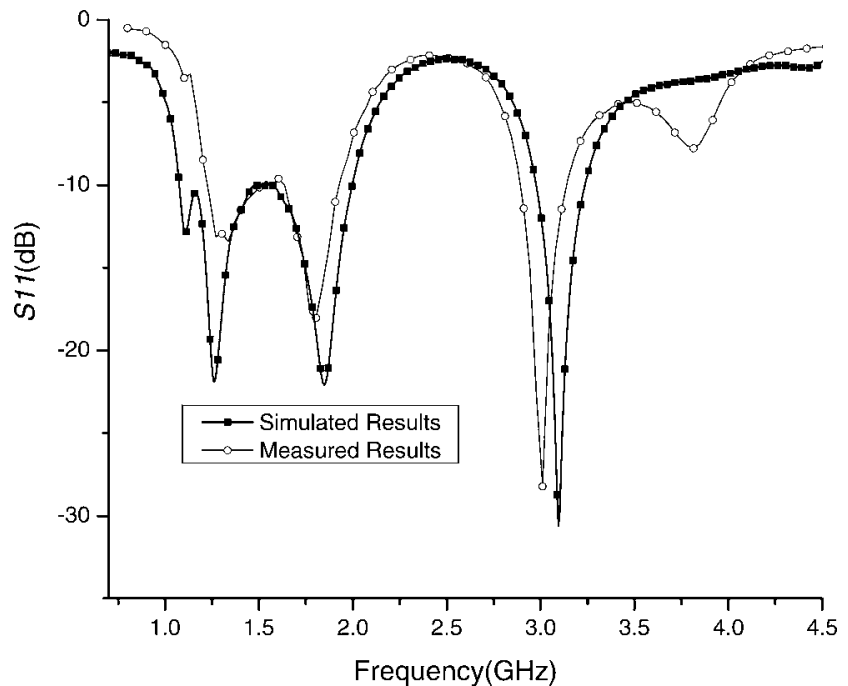

Figure 10 Comparison of the simulated and measured S11 for Antenna $C$

\subsection{Current distribution}

The principles of dual-frequency operation can be seen in the simulated current distribution plots in Figs. 6 and 7. It is shown in Fig. $6 a$ that the proposed antenna (named Antenna B, below) is well matched for the low-frequency mode, when the length of the microstrip line $L s$ is selected as $2 \mathrm{~mm}$. There is a strong interaction with the concentric split-ring and the resonant frequency is $1.165 \mathrm{GHz}$, which is below the resonant frequency of the unloaded annular-slot. For this antenna, the current distribution for the upper frequency of $1.85 \mathrm{GHz}$ indicates reduced interaction with the concentric slot, and this mode is closer to the unloaded annular-slot resonance. This can be seen in Fig. 6b. For a longer feedline coupling (Antenna A), the lower frequency mode at $1.78 \mathrm{GHz}$ is dominated by the annular-slot resonance and the upper band employs split-ring loaded higher modes. These modes can be seen in Figs. $7 a$ and $7 b$. Hence, the matching power to the various modes is controllable by the parameter $L$ s.

\section{Measured results}

To show design flexibility of the geometry, three dual-band slot antennas were fabricated and measured, which are printed on the FR4 substrate with various parameters as listed in Table 1. Table 2 summarises the performance of the three antennas with measured and simulated results. They are listed as antennas A, B and C. Table 3 illustrates the sensitivity of centre-frequency and bandwidth of the antenna to geometric parameters, which is useful as a design guide.

The measured results are in agreement with the simulated results. Antenna A provides a wide bandwidth for both bands as follows: as shown in Fig. 8, for Antenna A $(L s=9 \mathrm{~mm})$, the bandwidth of the lower frequency is
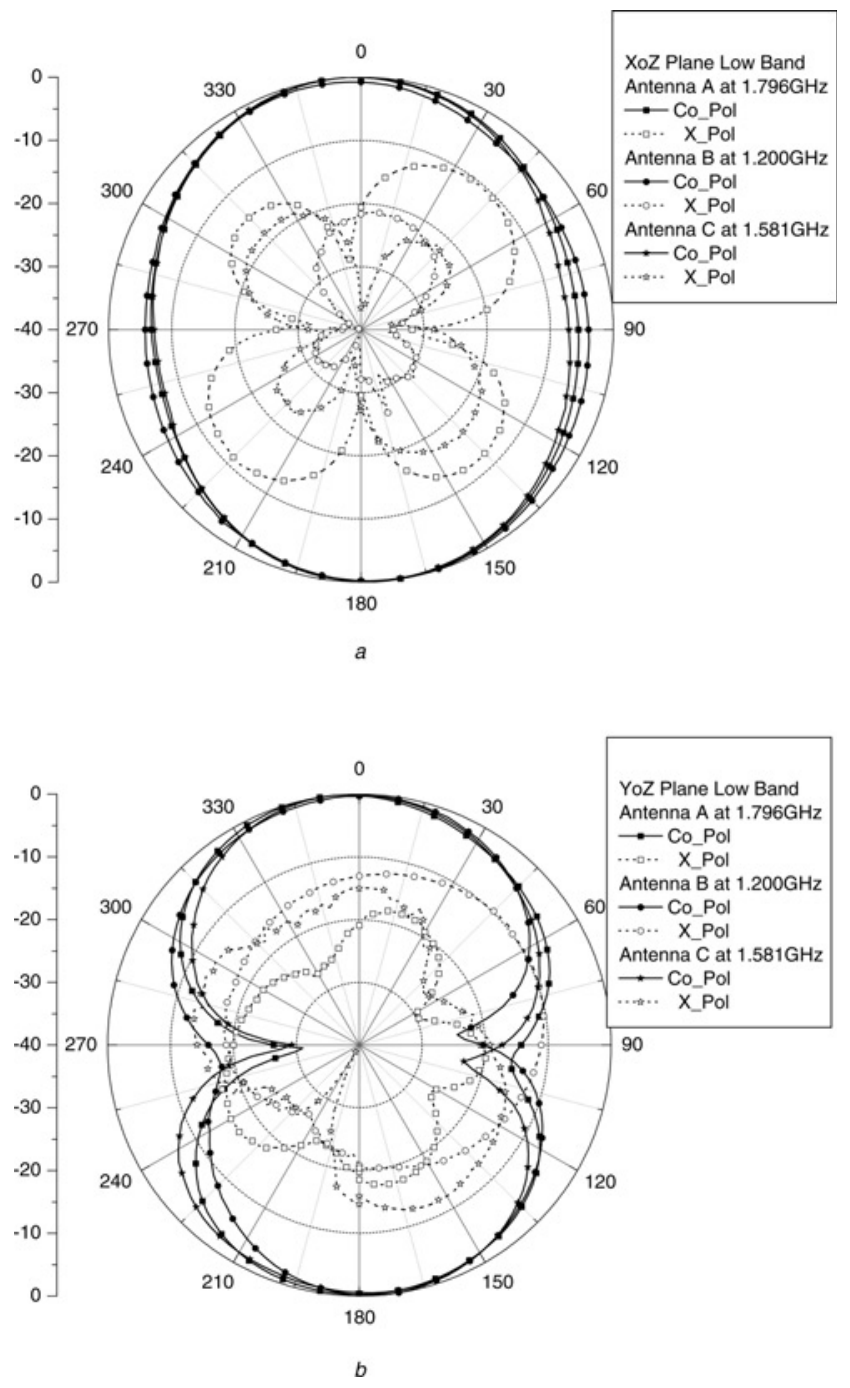

Figure 11 Measured radiation patterns for the lowerfrequency band for Antennas $A, B$ and $C$

a XoZ plane

$b$ YoZ plane

about $26.9 \%(483 \mathrm{MHz})$ from $1.554 \mathrm{GHz}$ to $2.037 \mathrm{~Hz}$, and the bandwidth of the upper frequency is about $32.5 \%$ $(1718 \mathrm{MHz})$ from 4.438 to $6.156 \mathrm{GHz}$. The frequency ratio is $2.95: 1$

The proposed antenna, Antenna B $(L \mathrm{~s}=2 \mathrm{~mm})$ provides maximum compactness and the frequency of the lower band is much lower; the bandwidth of the lower frequency is about $15.3 \%(184 \mathrm{MHz})$ from 1.108 to $1.292 \mathrm{GHz}$, and the bandwidth of upper frequency is about $29.0 \%(536 \mathrm{MHz})$ from 1.582 to $2.118 \mathrm{GHz}$. This is shown in Fig. 9. The frequency ratio is $1.54: 1$.

Antenna $\mathrm{C}(L \mathrm{~s}=11 \mathrm{~mm})$ is shown to provide a very wide bandwidth for the first band. It presents wide impedance characteristics with a bandwidth of $45.0 \%$ for the lower band. Measurements shown in Fig. 10 indicate that this band covers $1.227-1.935 \mathrm{GHz}$ whereas the upper band covers $2.890-3.143 \mathrm{GHz}$ (45 and 8.4\%, respectively). 

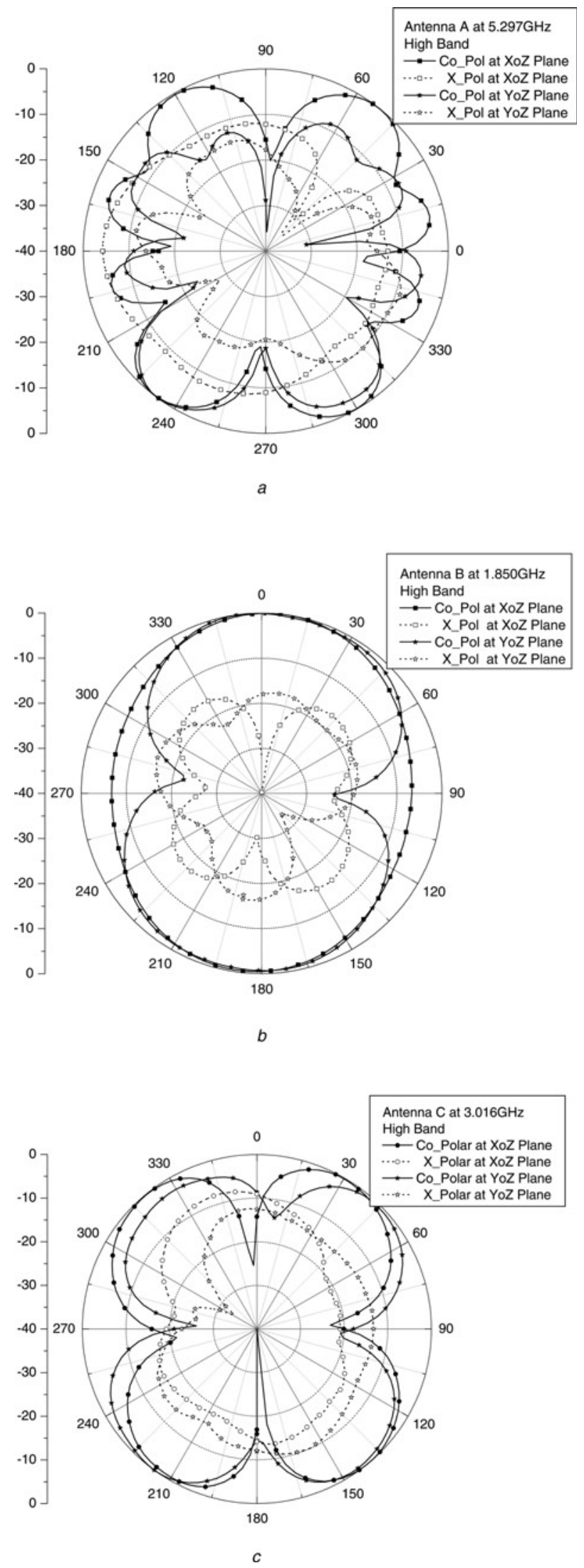

Figure 12 Measured radiation patterns for the highfrequency band for
a Antenna $\mathrm{A}$
$b$ Antenna B
c Antenna C

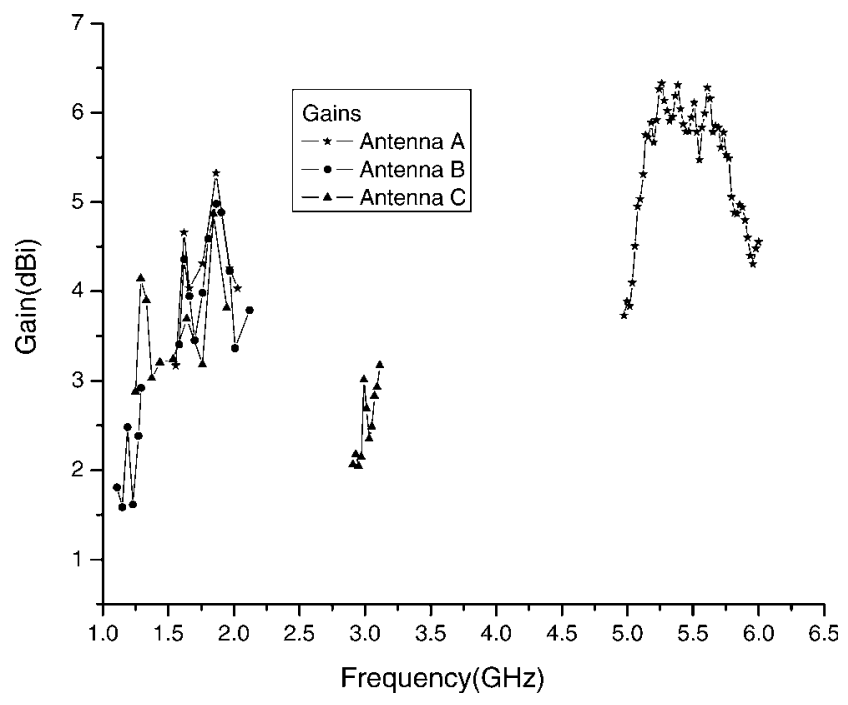

Figure 13 Measured peak gains for Antennas $A, B$ and $C$

Figs. $11 a$ and $11 b$ show the measured radiation patterns at the lower centre-frequency for Antennas A, B and C, respectively. It is seen that the radiation patterns of the three antennas depend on the operating mode. In Figs. 11a and $11 b$, the patterns for all antennas in the lower band are bidirectional, with good cross-polarisation properties. Figs. $12 a-12 c$ show the measured radiation patterns at the high band for Antennas A, B and C, respectively. The pattern for Antenna B (Fig. 12b) illustrates a broadside pattern with the cross-polarisation level better than $10 \mathrm{~dB}$ for the high band. However, it is observed from Fig. 12a that Antenna A exhibits a higher order mode pattern with very poor cross-polarisation. The pattern for Antenna C also exhibits poor cross-polarisation as shown in Fig. 12c. These patterns can be suitable for indoor wireless communications and ad hoc networks [24, 25] where crosspolar performance is not a requirement and where channels are dominated by rich Rayleigh fading. Fig. 13 shows the measured peak gains for the low- and high-frequency bands for Antennas A, B and C.

\section{Conclusions}

A dual-frequency planar annular-slot antenna is realised providing wide bandwidth characteristics. Very wide bandwidths are achieved for one or both bands by controlling the modes of operation. Frequency ratios in the region of 1.5 to 3.0 are possible. Compared with the conventional annular-slot antenna, the centre frequency for the proposed slot antenna is reduced by about 30\% when the split-ring-slot is strongly coupled. By adjusting the various geometric parameters, the frequency ratio and the bandwidth of each band can be easily controlled.

\section{Acknowledgment}

This work was funded by Science Foundation Ireland. 


\section{References}

[1] BATCHELOR J.C., LANGLEY R.J.: 'Microstrip ring antennas operating at higher order modes for mobile applications', IEE Proc. H, Microw., Antennas Propag., 1995, 141, (2), pp. $151-155$

[2] GUO Y.X., LUK K.M., LEE K.F.: 'L-probe proximity-fed annular ring microstrip antennas', IEEE Trans. Antennas Propag., 2001, 49, (1), pp. 19-21

[3] BAO X.L., AMMANN M.J.: 'Comparison of several novel annular-ring microstrip patch antennas for circular polarization', J. Electromag. Waves Appl., 2006, 20, (11), pp. 1427-1438

[4] Parsche, Fracis Eugene, US. Patent No. 6992630, Annulal ring Antenna

[5] BATCHELOR J.C., LANGLEY R.J.: 'Microstrip annular ring slot antennas for mobile applicaiotns', Electron. Lett., 1996, 32, (18), pp. 1635-1636

[6] ShARMA S.K., ShAFAI L., JACOB N.: 'Investigation of wideband microstrip slot antenna', IEEE Trans. Antennas Propag., 2004, 52, (3), pp. 865-872

[7] TEHRANI H., CHANG K.: 'Multifrequency operation of microstrip-fed slot-ring antennas on thin low-dielectric permittivity substrates', IEEE Trans. Antennas Propag., 2002, 50, (9), pp. 1299-1308

[8] yoshimuRa y.: 'A microstripline slot antenna', IEEE Trans. Microw. Theory Tech., 1972, 20, (11), pp. 760-762

[9] HONG C.S.: 'Large bandwidth circular slot at resonance with directional radiation', Electron. Lett., 1988, 24, (23), pp. 1449-1450

[10] JANG Y.W.: 'Experimental study of wideband printed annular slot antenna with cross-shaped feedline', Electron. Lett., 2002, 38, (22), pp. 1305-1307

[11] HIROSE K., NAKANO H.: 'Dual-loop slot antenna with simple feed', Electron. Lett., 1989, 25, (18), pp. 1218-1219

[12] LI R.L., PAN B., TRAILlE A.N., LASKAR J.: 'Development of a cavity-backed circularly polarized slot/strip loop antenna with a simple feeding structure', IEEE Trans. Antennas Propag., 2008, 56, (4), pp. 1155-1162

[13] WANG C.J., LEE J.J., HUANG R.B.: 'Experimental studies of a miniaturized CPW-fed slot antenna with the dual-frequency operation', IEEE Antennas Wirel. Propag. Lett., 2003, 2, pp. 151-154

[14] CHEN S.Y., HSU P.: 'Broad-band radial slot antenna fed by coplanar waveguide for dual-frequency operation', IEEE Trans. Antennas Propag., 2005, 53, (11), pp. 3448-3452

[15] WU J.W., HSIAO H.M., LU J.H., CHANG S.H.: 'Dual broadband design of rectangular slot antenna for 2.4 and $5 \mathrm{GHz}$ wireless', Electron. Lett., 2004, 40, (23), pp. 1461-1463

[16] omar A.A., SCARDELletTI M.C., HejAZI Z.M., DIB N.: 'Design and measurement of self-matched dual-frequency coplanar waveguide-fed-slot antennas', IEEE Trans. Antennas Propag., 2007, 55, (1), pp. 223-226

[17] Buerkle A., Sarabandi K., mosallael h.: 'Compact slot and dielectric resonator antenna with dual-resonance, broadband characteristics', IEEE Trans. Antennas Propag., 2005, 53, (3), pp. 1020-1027

[18] WONG M., SEBAK A.R., DENIDNI T.A.: 'Analysis of a dual-band dual slot omnindirectional stripline antenna', IEEE Antennas Wirel. Propag. Lett., 2007, 6, pp. 199-202

[19] SZE J.Y., HSU C.I.G., HSU S.C.: 'Design of a compact dual-band annular-ring slot antenna', IEEE Antennas Wirel. Propag. Lett., 2007, 6, pp. 423-426

[20] LIN Y.C., HUNG K.J.: 'Design of dual-band slot antenna with double T-match stubs', Electron. Lett., 2006, 42, (8), pp. 438-439

[21] LI B., LEUNG K.W.: 'Dielectric-covered dual-slot antenna for dualband applications', IEEE Trans. Antennas Propag., 2007, 55, (6), pp. 1768-1773

[22] LIU J.C., ZENG B.H., WU C.Y., CHANG D.C.: 'Synthesis technique of double-ring slot antenna with tree-shaped coupling strip for dual broadband applications', IEE Proc., Microw. Antennas Propag., 2006, 153, (6), pp. 510-515

[23] JANASWAMY R., SCHAUBERT D.H.: 'Characteristic impedance of a wide slotline on low- permittivity substrates', IEEE Trans. Microw. Theory Technol., 1984, 34, (8), pp. 900-902

[24] eCONOMOU L., LANGley R.J.: 'Patch antenna equivalent to simple monopole', Electron. Lett., 1997, 33, (9), pp. 717-728

[25] GUO Y.J., PAEZ A., SADEGHZADEH R.A., BARTON S.K.: 'A circular patch antenna for radio LAN's', IEEE Trans. Antennas Propag., 1997, 45, (1), pp. 177-178 